Eixo Temático: Educação Não-Formal

\title{
ET-08-005 \\ O MUSEU E O ENSINO DE CIÊNCIAS: UMA ABORDAGEM LÚDICA
}

Geryticia Ledyanne de Santana Santos ${ }^{12}$, Roberta Kimbelly Farias de Oliveira ${ }^{1}$, Isabella Beatriz Marinho Santos ${ }^{1}$, Maria Isabel de Assis Lima ${ }^{1}$, Daffany Luana dos Santos ${ }^{1}$

${ }^{1}$ Licenciandas do curso de Ciências Biológicas, Universidade Federal de Pernambuco (UFPE). geryticia.ledyanne15@gmail.com

$$
\text { http://dx.doi.org/10.21472/congrebio2016.et-08-005 }
$$

\section{RESUMO}

Dentre as diversas dificuldades encontradas por professores da educação básica de ciências e biologia estão à extensa grade curricular e os problemas encontrados na própria escola. Sendo assim, a utilização de espaços que transcendam a sala de aula e uma complementação do que é visto na escola é algo de grande importância no processo de ensino e de aprendizagem. Um dos conteúdos em que os alunos têm maior dificuldade de aprender é fisiologia humana. Pensando nessa perspectiva, desenvolveu-se uma oficina lúdica intitulada Trilha Digestória no museu interativo Espaço Ciência, em Olinda. A oficina teve um resultado satisfatório e contou com a participação de alunos da educação básica, professores e monitores do museu.

Palavras-chave: Ciências; Museus; Lúdico.

\section{INTRODUÇÃO}

Devido a uma extensa grade curricular e as variadas dificuldades encontradas em escolas brasileiras, os professores acabam não abordando todos os conteúdos previstos nos parâmetros curriculares nacionais, ou trabalhando-os de forma superficial. Sendo assim, a utilização de espaços que transcendam a sala de aula e uma complementação do que é visto na escola é algo de grande importância no processo de ensino e de aprendizagem. Nesses espaços, ocorre uma grande conexão entre o que o aluno já sabe, com aquilo que ele acaba de aprender, minimizando a frequência da tão famosa pergunta "Por que eu tenho que aprender isso?”.

Ausubel (apud MOREIRA, 1999 p.155) afirma que "A essência do processo de aprendizagem significativa é que as ideias expressas simbolicamente são relacionadas às informações previamente adquiridas pelo aluno através de uma relação não arbitrária e substantiva (não literal). Uma relação não arbitrária e substantiva significa que as ideias são relacionadas a algum aspecto relevante existente na estrutura cognitiva do aluno, como por exemplo, uma imagem, um símbolo, um conceito ou uma proposição”.

Baseado nessa teoria proposta por Ausubel torna-se sabido que a utilização de pontes entre um conteúdo já assimilado, com um novo conteúdo, é imprescindível para uma eficácia no processo de aprendizagem. No âmbito escolar, muitos docentes acabam negligenciando alguns aspectos dessa teoria, contudo, sabe-se que:

“a aprendizagem significativa tem vantagens notáveis, tanto do ponto de vista do enriquecimento da estrutura cognitiva do aluno como do ponto de vista da lembrança posterior e da utilização para experimentar novas aprendizagens, 
fatores que a delimitam como sendo a aprendizagem mais adequada para ser promovida entre os alunos. (PELIZZARI et al., 2002).

Assim, espaços educativos que promovam a aprendizagem significativa são de grande valia, sejam estes ambientes formais ou não-formais. Um dos espaços que ultrapassam a sala de aula, mas que também possuem papel educativo (por meio de uma educação não-formal), são os museus. Segundo Marandino (2008, p.12)

“os museus vêm sendo caracterizados como locais que possuem uma forma própria de desenvolver sua dimensão educativa. Identificados como espaços de educação não-formal, essa caracterização busca diferenciá-los das experiências formais de educação, como aquelas desenvolvidas na escola, e das experiências informais, geralmente associadas ao âmbito da família”

\section{OBJETIVOS}

Implantar uma oficina no Espaço Ciência sobre o sistema digestório, contribuindo dessa forma para a aprendizagem de monitores e visitantes do local. E também, complementar de forma lúdica o que os alunos aprendem na escola, ou que pelo menos deveria aprender.

\section{METODOLOGIA}

Elaboramos uma oficina que visou ensinar o sistema digestivo de uma forma mais lúdica e construtivista, pois como atesta Santos (1997, p.12): "O desenvolvimento do aspecto lúdico facilita a aprendizagem, o desenvolvimento pessoal, social e cultural, colabora para uma boa saúde mental, prepara para um estado interior fértil, facilita os processos de socialização, comunicação, expressão e construção do conhecimento”.

Mostramos aos alunos através de um modelo anatômico de resina os órgãos que fazem parte do sistema digestivo; fizemos atividades práticas fundamentadas nas reações químicas que ocorrem no processo da digestão: Ação da saliva nos alimentos, importância da mastigação, sentindo os sabores, movimentos peristálticos, acidez do suco gástrico, detergente da digestão, e a absorção de água no corpo; Ao final realizamos um jogo onde os alunos montaram uma trilha com gravuras dos órgãos que compõem o sistema digestivo e em seguida associaram o órgão à sua função. Antes da realização da oficina com os visitantes do Espaço Ciência fizemos uma breve capacitação com os monitores, explicando o passo a passo da oficina e debatendo sobre a relevância da mesma.

No decorrer da oficina procuramos instigar a participação dos visitantes para que alcançássemos êxito no processo de ensino e de aprendizagem. Braz da Silva (1998) assevera sobre a necessidade de que os alunos "se sintam seduzidos pelo que lhes é apresentado, que encontrem significação a partir das atividades desenvolvidas, para que possam compreender os enunciados científicos e a construção da própria ciência”.

A trilha digestiva foi apresentada aos monitores, a estudantes do projeto Ciência Jovem, a professores, a alunos do ensino fundamental II do Educandário Beatriz França, de Limoeiro, e alunos do $2^{\circ}$ ano do ensino médio da Escola de Referência em Ensino Médio Jornalista Jáder de Andrade, de Timbaúba. E essa abordagem prática deu-se pela grande importância de sairmos de uma teoria que muitas vezes é abstrata, para uma aprendizagem mais palpável e "as atividades práticas, quando bem aplicadas, utilizam a problematização e o raciocínio como estratégias, formando sujeitos motivados, com competências éticas, políticas e sociais, dotados de raciocínio crítico e responsabilidade” Cardoso (2013). 

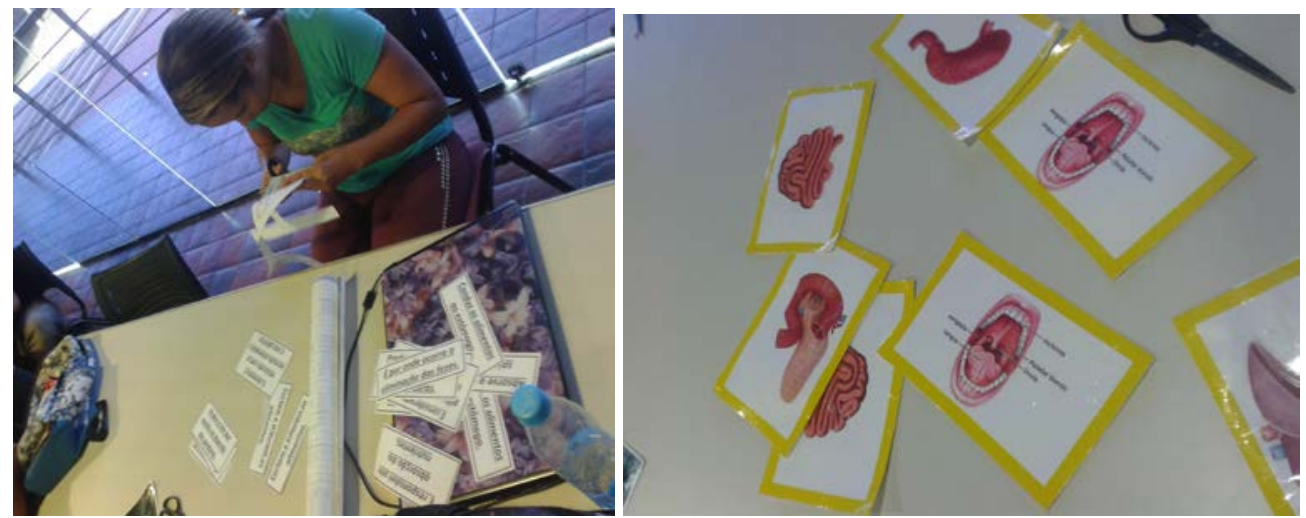

Figuras 1 e 2. Confecção de elementos da oficina

\section{MATERIAIS}

* Prática 1: A ação da saliva nos alimentos que ingerimos: Conta-gotas, tintura de iodo, 2 copos plásticos de café, 2 tubos de ensaio numerados; água; amido.

* Prática 2: A importância da boa mastigação: Dois copos com água, dois comprimidos efervescentes.

* Prática 3: Sentindo sabores: Quatro conta-gotas de forma que em cada um haja uma substância (suco de limão, chá de romã, água com açúcar e água com sal), colheres e açúcar.

* Prática 4: Fazendo os movimentos peristálticos: Uma meia-calça, uma bolinha que pode ser de isopor, biscoitos.

* Prática 5: O suco gástrico e sua acidez: Vinagre, um copo plástico de café, leite.

* Prática 6: O detergente da digestão: Dois copos, água; detergente, óleo de cozinha.

* Prática 7: A absorção de água em nosso corpo: Tubo de ensaio, água, esponja.

* Prática 8: Montagem da trilha digestória: Gravuras dos órgãos e cartões com as funções de cada um.

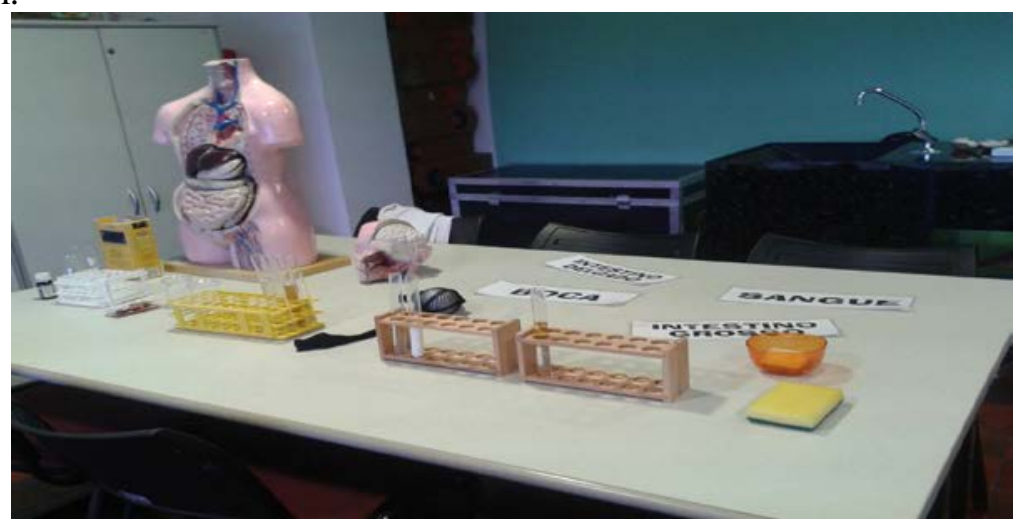

Figura 3. Bancada com materiais utilizados.

\section{PRÁTICAS REALIZADAS}

1. A ação da saliva nos alimentos que ingerimos: Colocamos a solução de amido em dois tubos de ensaio, posteriormente pedimos que um dos participantes colocasse sua própria saliva em um dos tubos. Cerca de 20 minutos depois, colocamos uma gota de iodo em cada tubo e perguntamos o que eles estavam observando e questionamos porque apenas um dos tubos apresentou uma coloração roxa. 
2. A importância da boa mastigação: Foi colocada a mesma medida de água em dois béqueres. Em seguida pedimos para que os visitantes segurassem os dois comprimidos efervescentes, conforme solicitado um deles foi triturado e o outro permaneceu inteiro. Depois pedimos para que eles colocassem, ao mesmo tempo, o comprimido inteiro em um béquer e o triturado dentro de outro béquer. Eles observaram e associamos o que ocorreu com o processo de mastigação.

3. Sentindo sabores: Comentamos com os alunos sobre as regiões da língua que sentem os sabores. Em seguida, pedimos que dois deles secassem a língua e pingamos água com açúcar na língua deles. Enquanto a língua permanecia seca eles não sentiam o sabor e então fizemos uma breve discussão em volta disso.

4. Fazendo os movimentos peristálticos: Colocamos uma bolinha dentro de uma meiacalça e simulamos os movimentos peristálticos do esôfago. Explicamos que a bolinha representava o bolo alimentar, enquanto a meia representava o esôfago. Em seguida, distribuímos algumas bolachas entre os visitantes, pedimos que eles colocassem a mão sobre a garganta no momento da deglutição e informassem o que percebiam.

5. O suco gástrico e sua acidez: Colocamos leite em um tudo de ensaio e em seguida chamamos um participante para adicionar o vinagre que estava em outro tubo de ensaio. Enquanto observavam fizemos perguntas para estimular a curiosidade e em seguida relacionamos a reação que eles estavam observando com a ação do suco gástrico.

6. O detergente da digestão: Colocamos água e óleo em um tubo de ensaio. Em seguida, chamamos um visitante para mexer bem o tubo de ensaio e eles confirmaram o que eles próprios nos disseram “Água e óleo não se misturam”. Posteriormente outro visitante acrescentou detergente ao tudo e mexeu. Eles verificaram o que ocorreu e debatemos sobre os resultados.

7. A absorção de água em nosso corpo: Colocamos água dentro de um béquer e em seguida despejamos a água sobre uma esponja. Observamos e discutimos os resultados.

\section{RESULTADOS E DISCUSSÕES}

No primeiro contato observamos que os participantes não lembravam ao certo o processo da digestão, eles tinham informações aleatórias e foi através delas que iniciamos a oficina. No decorrer das atividades que estávamos executando, pudemos observar um grande interesse por partes dos visitantes. Eles estavam extremamente envolvidos com tudo que estava sendo exposto.

Ao fim de cada experimento pudemos verificar que eles realmente haviam aprendido algo. Comentários como: “A saliva tem enzima!”, “Não tem mais amido por causa da enzima da saliva!", "Tem que mastigar muito pra o alimento ser absorvido rápido", "O vinagre talhou o leite!” fizeram com que percebêssemos esse resultado positivo. Eles conseguiam explicar o que estava acontecendo, não usavam termos técnicos nem bioquímicos, mas explicavam de uma forma que conseguíamos entender. Cada um dizia o que achava que aconteceu e através disso construíamos uma explicação.

Com relação à montagem da trilha com os cartões, notamos a empolgação deles para montar corretamente e a satisfação ao concluir a atividade. Das oito equipes que montaram a trilha, duas delas erraram quando foram associar o órgão com a sua função. Porém em seguida, debatemos os erros cometidos por eles no intuito que eles reconhecessem o erro e pudessem consertá-lo. Os alunos interagiram muito e sempre se mostravam empolgados em participar. Eles demonstraram grande interesse pelos experimentos feitos e colaboraram surpreendentemente conosco. 


\section{CONSIDERAÇÕES FINAIS}

O Espaço Ciência é um excelente local para observarmos e vivenciarmos a educação propiciada por espaços não formais. Dentro dele não só compreendemos a interdisciplinaridade como podemos experimentá-la. Isso só comprova a importância e a eficácia do ensino de ciências em museus. Verificamos também, que a utilização de atividades práticas e divertidas no ensino de ciências cria no aluno o desejo de "querer aprender" refletindo em um resultado positivo no contexto atual em que a educação se encontra.

\section{REFERÊNCIAS}

BRAZ DA SILVA, A. M. T. Representações sociais: uma contraproposta para o estudo das concepções alternativas em ensino de Física. Rio de Janeiro: Universidade Federal do Rio de Janeiro, 1998. (Tese de Doutorado).

CARDOSO, P. S. O uso de atividades práticas no ensino de Ciências: na busca de melhores resultados no processo ensino-aprendizagem. Lajeado: Centro Universitário UNIVATES, 2013 (Monografia de graduação).

MARANDINO, M. (Org). Educação em museus: a mediação em foco. São Paulo, 2008.

MOREIRA, M. A. Teorias de aprendizagens. São Paulo: EPU, 1995.

PELLIZZARI, A.; KRIEGL, M. L.; BARON, M. P.; FINCK. N. T.; DOROCINSKI, S. I. Teoria da aprendizagem significativa segundo Ausubel. Rev. PEC, v. 2, n. 1, p. 37-42, 2001-2002.

SANTOS, S, M. P. (Org). Brinquedoteca: o lúdico em diferentes contextos. Rio de Janiero: Vozes, 1997. 